Mathematical Modelling And Analysis

Volume 20 Number 4, July 2015, 443-456

http://dx.doi.org/10.3846/13926292.2015.1064486

(c) Vilnius Gediminas Technical University, 2015
Publisher: Taylor\&Francis and VGTU

http://www.tandfonline.com/TMMA

ISSN: $1392-6292$

eISSN: 1648-3510

\title{
Freezing of Biological Tissues During Cryosurgery Using Hyperbolic Heat Conduction Model
}

\author{
Sonalika Singh and Sushil Kumar \\ Department of Applied Mathematics and Humanities, S. V. National \\ Institute of Technology \\ Surat-395007, India \\ E-mail(corresp.): singhsonalika01@gmail.com \\ E-mail: sushilk@ashd.svnit.ac.in
}

Received June 5, 2013; revised June 11, 2015; published online July 15, 2015

\begin{abstract}
This paper considers hyperbolic heat conduction model for biological tissue freezing during cryosurgery with non ideal property of tissue, metabolism and blood perfusion. Mathematical model is solved numerically using finite difference method to obtain temperature distribution and phase change interfaces in tissue during freezing. The effects of phase lag of heat flux in hyperbolic bio-heat model on freezing process are studied. Comparative study of parabolic and hyperbolic bio-heat models is also made here.
\end{abstract}

Keywords: heat conduction, finite difference method, heat conduction equation.

AMS Subject Classification: 35L10; 65M06; 92B05; 93A30.

\section{Introduction}

Phase change heat transfer is a broad field that finds applications in various engineering disciplines like in the making of ice, the freezing of food, the solidification of metals and alloy, thermal energy storage, cryosurgery and cryopreservation. Freezing and thawing processes are two most important process of phase change associated with high heat transfer rate. The heat transfer involved in phase change is essential in biomedical applications. Two potential applications of heat transfer with phase change in biomedical are cryopreservation and cryosurgery. Cryopreservation is applied to enhance survival of biological materials such as cell, tissues, organs, etc; while cryosurgery is applied to destruct undesired tissues using a freezing process. Cryosurgery is a technique to treat tumor and can be used inside the body and on the skin using extreme cold which is obtained using liquid nitrogen through cryoprobe into or on the target region. The aim of cryosurgery is to maximize the damage 
to undesired tissues within the define domain and minimize the injury to the surrounding healthy tissues $[4,9]$.

Various models have been proposed to model the heat transport phenomena in blood perfused tissue e.g. Pennes model [31], The Chen and Holmes $(\mathrm{CH})$ model [8], The Weinbaum, Jiji and Lemons (WJL) model [20,42], The Weinbaum and Jiji (WJ) model $[20,41,42]$. Pennes bio-heat equation is the most widely applied model for temperature distribution in the living biological tissues. This is the earliest model for energy transport in tissues and is given as [31]

$$
\rho c \frac{\partial T}{\partial t}=-\frac{\partial q}{\partial x}+(\rho c)_{b} w_{b}\left(T_{b}-T\right)+Q_{m},
$$

where $\rho$ is density of tissue; $k$, thermal conductivity; $c_{b}$, specific heat of blood; $w_{b}$, blood perfusion; $T$, temperature; $t$, time; $T_{b}$, arterial blood temperature and $Q_{m}$ is the metabolic heat generation in the tissue. In Pennes bio-heat equation, the heat conduction in biological tissue is modeled by using Fourier's law

$$
q(t, x)=-k \nabla T(t, x),
$$

where $q(t, x)$ and $T(t, x)$ represents heat flux and temperature at position $x$ and time $t$ respectively.

Fourier's law assumes that heat flux $q$ and temperature change $\nabla T$ at any point $x$ appear at the same time instant $t$. This implies that thermal signals propagate with an infinite speed [25]. In fact, heat is always found to propagate at finite speed. On the other hand, biological tissue are inhomogeneous where heat flux responds to temperature gradient via relaxation behavior. This has led to work of searching for new constitutive models. Cattaneo [7] and Vernotte [39] simultaneously suggested a modified heat flux model as

$$
q(t+\tau, x)=-k \frac{\partial T(t, x)}{\partial x},
$$

where $\tau$ is thermal relaxation time for heat flux. The first order Taylor expansion of $q$ in the equation (1.3) gives

$$
q+\tau \frac{\partial q}{\partial t}=-k \frac{\partial T}{\partial x} .
$$

Equation (1.4) is well known as Cattaneo-Vernotte's constitutive relation. Suppose $\tau$ is small in the equation (1.4), so the first order Taylor expansion of $q(t+\tau, x)$ is an accurate representation for the conduction heat flux. Elimination of $q$ between equations (1.1) and (1.4) gives

$$
\tau \rho c \frac{\partial^{2} T}{\partial t^{2}}+\left(\rho c+\tau \rho_{b} c_{b} w_{b}\right) \frac{\partial T}{\partial t}=k \frac{\partial^{2} T}{\partial x^{2}}+Q_{m}+\rho_{b} c_{b} w_{b}\left(T_{b}-T\right) .
$$

This equation (1.5) is well known as single phase lag bio-heat equation. It is also called as hyperbolic bio-heat equation as it is hyperbolic in nature and reduced to parabolic equation for $\tau=0$.

Various authors have studied the phase change phenomena in tissues using classical Pennes equation $[21,22,24,44]$. The heat transfer in tissues, using 
hyperbolic bio-heat equation without phase change has also been studied by Liu [26]. Ahamdikia et al. [2] presented the analytical solution of the Fourier and non-Fourier bio-heat transfer models of laser irradiation of skin tissue. Čiegis et al. [11] used the hyperbolic two step model to describe the interaction of ultrashort laser pulses with metals and semiconductors. Torabi et al. [36,38] solved two dimensional hyperbolic heat conduction equations analytically and numerically. Ahamdikia et al. [1] studied the freezing in tissue using hyperbolic heat conduction model. In their study, they assumed the temperature discontinuity at solid-liquid interface and neglected the source of the heat due to blood perfusion and metabolism. They applied isothermal and non-isothermal phase change in order to simulate heat transfer in cryopreservation. Blood perfusion and metabolic heat generation also have important effect on heat transfer in tissues $[15,34,35,44]$.

In present study, non-Fourier heat conduction model for biological tissue freezing has been proposed. Non-ideal properties of tissue, metabolism and blood perfusion in tissues have been taken into consideration. Enthalpy formulation and finite difference method are used for numerical solutions. To study the effect of relaxation time for heat flux on freezing, temperature profiles in tissue and position of phase change interfaces are obtained for different values of relaxation time for heat flux $\tau$.

\section{Mathematical Model}

\subsection{Governing equation}

Using the equation (1.5) the non-Fourier bio-heat equation in frozen region and unfrozen region are given below.

In frozen region:

$$
\tau \rho_{f} c_{f} \frac{\partial^{2} T_{f}}{\partial t^{2}}+\rho_{f} c_{f} \frac{\partial T_{f}}{\partial t}=k_{f} \frac{\partial^{2} T_{f}}{\partial x^{2}} \quad \text { for } 0 \leq x<s(t) .
$$

In unfrozen region:

$$
\begin{gathered}
\tau \rho_{u} c_{u} \frac{\partial^{2} T_{u}}{\partial t^{2}}+\left(\rho_{u} c_{u}+\tau \rho_{b} c_{b} \omega_{b}\right) \frac{\partial T_{u}}{\partial t}=k_{u} \frac{\partial^{2} T_{u}}{\partial x^{2}}+Q_{m}+\rho_{b} c_{b} \omega_{b}\left(T_{b}-T_{u}\right) \\
\text { for } s(t)<x \leq l
\end{gathered}
$$

Conditions at phase change interface $x=x(t)$ are

$$
k_{f} \frac{\partial T_{f}(s, t)}{\partial x}-k_{u} \frac{\partial T_{u}(s, t)}{\partial x}=\rho L \frac{d s}{d t}+\tau \rho L \frac{d^{2} s}{d t^{2}}
$$

and

$$
T_{f}(s(t), t)=T_{u}(s(t), t)=T_{p h},
$$

where subscripts $u, f$ and $p h$ denote frozen, unfrozen and phase change respectively.

Major difficulties that arise in phase change heat transfer of biological tissue are its non-linearity due to variable disconnection between different phase 
region and unknown position of phase change interfaces. Enthalpy method, a non-front tracking method is used to formulate the mathematical model for freezing. Enthalpy is defined as a sum of sensible and latent heat. The basic feature of enthalpy method is that the evaluation of the latent heat is accounted by the enthalpy as well as the relation between enthalpy and temperature. The enthalpy method gives accurate solution, especially, for solidification of material in which a phase change exists over temperature range. Thus, for the solution purpose we consider the enthalpy formulation of single phase lag bio-heat equation for phase change problem associated with biological tissue freezing.

The relationship between the enthalpy and temperature can be defined in terms of the latent heat release as a linear function for non-isothermal phase change cases. Using enthalpy $H(T)=\int_{T_{r}}^{T} c d T$, where $T_{r}$ is reference temperature, temperatures are transformed into enthalpies in the following manner:

(i) Frozen region $\left(T<T_{m s}\right)$ :

$$
H=\int_{T_{m s}}^{T} c_{f} d T=c_{f}\left(T-T_{m s}\right) .
$$

(ii) Mushy region $\left(T_{m s} \leq T \leq T_{m l}\right)$ :

$$
H=\int_{T_{m s}}^{T} c_{a} d T+\frac{L}{\Delta T} \int_{T_{m s}}^{T} d T=c_{a}\left(T-T_{m s}\right)+\frac{L}{\Delta T}\left(T-T_{m s}\right) .
$$

(iii) Unfrozen region $\left(T>T_{m l}\right)$ :

$$
H=L+\int_{T_{m s}}^{T_{m l}} c_{a} d T+\int_{T_{m l}}^{T} c_{u} d T=L+c_{a} \Delta T+c_{u}\left(T-T_{m l}\right) .
$$

Thus, enthalpy and tissue temperature are related as $[5,17]$

$$
H= \begin{cases}c_{f}\left(T-T_{m s}\right), & T<T_{m s}, \\ c_{a}\left(T-T_{m s}\right)+\frac{L}{\Delta T}\left(T-T_{m s}\right), & T_{m s} \leq T \leq T_{m l}, \\ L+c_{a} \Delta T+c_{u}\left(T-T_{m l}\right), & T>T_{m l},\end{cases}
$$

where $L$ is latent heat of fusion, $c_{a}=\frac{c_{f}+c_{u}}{2}$ and $\Delta T=T_{m l}-T_{m s}$. Figure 1 shows the graphical interpretation of the relation between enthalpy and temperature. Using equation (2.5), equations (2.1)-(2.4) reduce in single equation as

$$
\tau \rho \frac{\partial^{2} H}{\partial t^{2}}+\left(\rho+\frac{\tau \rho_{b} c_{b} w_{b}}{c}\right) \frac{\partial H}{\partial t}=k \frac{\partial^{2} T}{\partial x^{2}}+Q_{m}+\rho_{b} c_{b} w_{b}\left(T_{b}-T\right) .
$$

\subsection{Assumptions}

(i) Heat conduction follows non-Fourier law of heat conduction. 


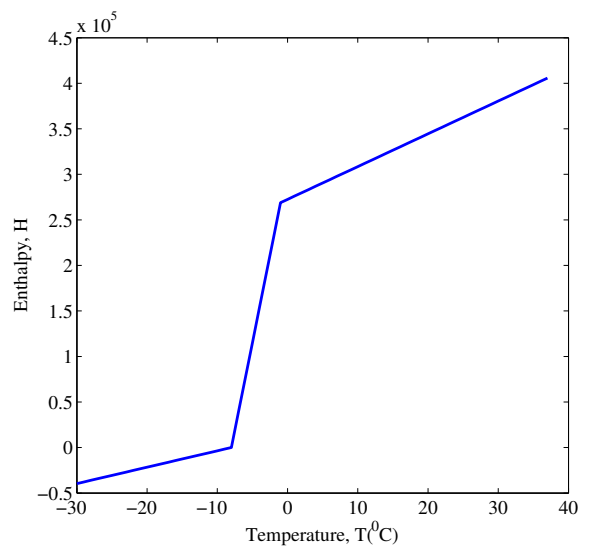

Figure 1. Graphical interpretation of enthalpy versus temperature.

(ii) Heat source due to metabolism and blood perfusion is present when tissue is not frozen $[14,15]$.

(iii) Non-ideal property of tissue is used with liquidus and solidus temperature as $-1{ }^{\circ} \mathrm{C}$ and $-8{ }^{\circ} \mathrm{C}$ respectively [32].

(iv) Thermo-physical properties are different in frozen and unfrozen region.

(v) One-dimensional model has been considered.

\subsection{Initial condition and boundary conditions}

Initial and boundary conditions for equation (2.6) are as follows:

$$
\begin{array}{lll}
T_{p}(x, t)=T_{0}, & p=u, f \quad \text { at } t=0, \\
\frac{\partial T_{p}(x, t)}{\partial t}=0, & p=u, f & \text { at } t=0, \\
T_{p}(x, t)=T_{c}, & p=u, f & \text { at } x=0, \\
\frac{\partial T_{p}(x, t)}{\partial x}=0, & p=u, f & \text { at } x=l,
\end{array}
$$

where $T_{0}$ is body core temperature $37^{\circ} \mathrm{C}$ and $T_{c}$ is cryoprobe temperature $-196{ }^{\circ} \mathrm{C}$.

\section{Numerical Solution}

Phase change problems can be solved using finite difference method (FDM) $[1,15,16,21,22,22,23,28,34]$, finite element method(FEM) $[6,12,19,29,30,35,40$, 43], boundary element method(FEM) $[14,18]$ or finite volume method (FVM). The finite element method and boundary element method successfully handle complex geometries, but it is recognize that they are consuming more time in 
computing and programming. Because of their simplicity in formulation and programming, finite difference techniques are still the most popular at present. Finite volume method is used for hyperbolic heat conduction model in [11]. Čiegis et al. [10] have discussed about finite difference schemes for hyperbolic heat conduction equations.

Finite difference approximation has been used to solve the mathematical model. The space length $l$ is discretizing into $N$ equal parts with $N=\frac{l}{\Delta x}$. Considering $x_{i}=i \triangle x$ and $t_{n}=n \triangle t$, where $i$ and $n$ are space and time indexes respectively; $\triangle x$ and $\Delta t$ are the increment in space and time respectively. Introducing forward difference approximation to time derivative and central difference approximation to space derivative and second order time derivative at point $\left(x_{i}, t_{n}\right)$ in equation (2.6), we get

$$
\begin{aligned}
H_{i}^{n+1}= & \left(1+A_{i}^{n} F_{i}^{n}\right) H_{i}^{n}-A_{i}^{n} F_{i}^{n} H_{i}^{n-1}+D_{i}^{n} F_{i}^{n}\left(T_{i+1}^{n}+T_{i-1}^{n}-2 T_{i}^{n}\right) \\
& +E F_{i}^{n}\left(T_{b}-T_{i}^{n}\right)+F_{i}^{n} Q_{m},
\end{aligned}
$$

where $A_{i}^{n}=\frac{\tau \rho_{i}^{n}}{(\triangle t)^{2}} ; \quad B_{i}^{n}=\left[\frac{\rho_{i}^{n}}{(\triangle t)}+\frac{\tau \rho_{b} c_{b} w_{b}}{c_{i}^{n}(\triangle t)}\right] ; \quad F_{i}^{n}=\frac{1}{A_{i}^{n}+B_{i}^{n}} ; \quad D_{i}^{n}=\frac{k_{i}^{n}}{(\triangle x)^{2}}$; $E=\rho_{b} c_{b} w_{b}$.

Equation (3.1) gives the enthalpy at $(n+1)^{t h}$ time step. After getting the enthalpy at $(n+1)^{t h}$ level, temperature at $(n+1)^{t h}$ time step can be obtained by reverting equation (2.5) as follows.

$$
T= \begin{cases}\frac{H}{c_{f}}+T_{m s}, & H<0, \\ \frac{H \Delta T}{c_{a} \Delta T+L}+T_{m s}, & 0 \leq H \leq L+c_{a} \Delta T, \\ \frac{H-L-c_{a} \Delta T}{c_{u}}+T_{m l}, & H>L+c_{a} \Delta T .\end{cases}
$$

Once the new temperature field is obtained from enthalpy the process repeats. Isotherms at $-1^{\circ} \mathrm{C}$ and $-8^{\circ} \mathrm{C}$ give the position of upper and lower phase change interfaces respectively.

\section{Stability Analysis}

The stability analysis is important for the numerical solution of differential equation. Sharma et al. [37] and Hossein et al. [3] discussed stability analysis in case of finite difference method. On the basis of their study, in the present section we discuss the stability of finite difference scheme given by equation (3.1). The finite difference method is called stable in the form of $\|\cdot\|$, if there exists a constant $C>0$, independent of the space step and time step such that

$$
\left\|H^{n}\right\| \leq\left\|H^{0}\right\|, \quad n=1,2, \ldots
$$

The finite difference scheme (3.1) can be written as

$$
\begin{aligned}
H_{i}^{n+1}= & \left(1+A_{i}^{n} F_{i}^{n}\right) H_{i}^{n}-A_{i}^{n} F_{i}^{n} H_{i}^{n-1}+D_{i}^{n} F_{i}^{n}\left(T_{i+1}^{n}+T_{i-1}^{n}-2 T_{i}^{n}\right) \\
& +F_{i}^{n} Q_{m}+E F_{i}^{n}\left(T_{b}-T_{i}^{n}\right)
\end{aligned}
$$


or

$$
\begin{aligned}
c_{i}^{n+1} T_{i}^{n+1}= & \left(1+A_{i}^{n} F_{i}^{n}\right) c_{i}^{n} T_{i}^{n}-A_{i}^{n} F_{i}^{n} c_{i}^{n-1} T_{i}^{n-1}+D_{i}^{n} F_{i}^{n}\left(T_{i+1}^{n}+T_{i-1}^{n}-2 T_{i}^{n}\right) \\
& +E F_{i}^{n}\left(T_{b}-T_{i}^{n}\right)+F_{i}^{n} Q_{m} \\
= & \left(c_{i}^{n}+c_{i}^{n} A_{i}^{n} F_{i}^{n}-2 D_{i}^{n} F_{i}^{n}-E F_{i}^{n}\right) T_{i}^{n}-A_{i}^{n} F_{i}^{n} c_{i}^{n-1} T_{i}^{n-1}+E F_{i}^{n} T_{b} \\
& +D_{i}^{n} F_{i}^{n}\left(T_{i+1}^{n}+T_{i-1}^{n}\right)+F_{i}^{n} Q_{m},
\end{aligned}
$$

or

$$
\begin{aligned}
\left|c_{i}^{n+1} T_{i}^{n+1}\right|= & \left|c_{i}^{n}+c_{i}^{n} A_{i}^{n} F_{i}^{n}-2 D_{i}^{n} F_{i}^{n}-E F_{i}^{n}\right|\left|T_{i}^{n}\right|-\left|A_{i}^{n} F_{i}^{n} c_{i}^{n-1}\right|\left|T_{i}^{n-1}\right| \\
& +\left|E F_{i}^{n} T_{b}\right|+\left|D_{i}^{n} F_{i}^{n}\right|\left|T_{i+1}^{n}+T_{i-1}^{n}\right|+\left|F_{i}^{n} Q_{m}\right| .
\end{aligned}
$$

Taking the norm $\|\cdot\|$ of the above equation, it gives

$$
\begin{aligned}
\left\|c_{i}^{n+1} T_{i}^{n+1}\right\|_{L}^{\infty} \leq & \sup _{i}\left|c_{i}^{n}+c_{i}^{n} A_{i}^{n} F_{i}^{n}-2 D_{i}^{n} F_{i}^{n}-E F_{i}^{n}\right| \sup _{i}\left|T_{i}^{n}\right|+\sup _{i}\left|F_{i}^{n} Q_{m}\right| \\
& -\sup _{i}\left|A_{i}^{n} F_{i}^{n} c_{i}^{n-1}\right| \sup _{i}\left|T_{i}^{n-1}\right|+\sup _{i}\left|D_{i}^{n} F_{i}^{n}\right| \sup _{i}\left|T_{i+1}^{n}+T_{i-1}^{n}\right| \\
& +\sup _{i}\left|E F_{i}^{n} T_{b}\right|
\end{aligned}
$$

or

$$
\begin{aligned}
c_{i}^{n+1}|| T_{i}^{n+1} \|_{L}^{\infty} \leq & \sup _{i}\left|c_{i}^{n}+c_{i}^{n} A_{i}^{n} F_{i}^{n}-2 D_{i}^{n} F_{i}^{n}-E F_{i}^{n}\right| \sup _{i}\left|T_{i}^{n}\right|+\sup _{i}\left|F_{i}^{n} Q_{m}\right| \\
& -\sup _{i}\left|A_{i}^{n} F_{i}^{n} c_{i}^{n-1}\right| \sup _{i}\left|T_{i}^{n-1}\right|+\sup _{i}\left|D_{i}^{n} F_{i}^{n}\right| \sup _{i}\left|T_{i+1}^{n}+T_{i-1}^{n}\right| \\
& +\sup _{i}\left|E F_{i}^{n} T_{b}\right| .
\end{aligned}
$$

The above finite difference method is stable, if $\mid c_{i}^{n}+c_{i}^{n} A_{i}^{n} F_{i}^{n}-2 D_{i}^{n} F_{i}^{n}-$ $E F_{i}^{n} \mid \geq 0$, which implies that

$$
\max \frac{(\triangle t)^{2}\left\{2 k+\rho_{b} c_{b} w_{b}(\triangle x)^{2}\right\}}{(\triangle x)^{2}\left\{2 c \tau \rho+c \rho(\triangle t)+\tau \rho_{b} c_{b} w_{b}(\triangle t)\right\}} \leq 1
$$

\section{Results}

In this study, the numerical results are shown for the non-Fourier's bio-heat transfer with phase change during the solidification process. The values of parameters used are given in Table $1[13,23,28,32,33,34]$. The relaxation time for the numerical solution are taken as $\tau=0 s, \tau=1 s, \tau=5 s, \tau=10 \mathrm{~s}$ and $\tau=15 s[2,13,25,27,28]$. The hyperbolic model reduces to parabolic model for $\tau=0$.

The temperature distributions of the tissue at time $t=400 \mathrm{~s}$ and $t=800 \mathrm{~s}$ for different values of time relaxation are presented in Figure 2 and Figure 3 respectively. It is recognizable that when the value of $\tau$ move towards to zero, the hyperbolic solution move towards the parabolic solution. In Figure 2 and Figure 3 the temperature profiles for $\tau=0 s$ and $\tau=1 s$ are almost identical, but for increased value of $\tau$ difference between the hyperbolic and parabolic 
Table 1. Thermal properties of tissue.

\begin{tabular}{ll}
\hline Parameter & Value \\
\hline Density of unfrozen tissue $\left(\mathrm{kg} / \mathrm{m}^{3}\right)$ & 1000 \\
Specific heat of unfrozen tissue $\left(\mathrm{J} / \mathrm{kg}^{\circ} \mathrm{C}\right)$ & 3600 \\
Thermal conductivity of unfrozen tissue $\left(\mathrm{W} / \mathrm{m}^{\circ} \mathrm{C}\right)$ & 0.5 \\
Density of frozen tissue $\left(\mathrm{kg} / \mathrm{m}^{3}\right)$ & 1000 \\
Specific heat of frozen tissue $\left(\mathrm{J} / \mathrm{kg}^{\circ} C\right)$ & 1800 \\
Thermal conductivity of frozen tissue $\left(\mathrm{W} / \mathrm{m}^{\circ} C\right)$ & 2 \\
Density of blood $\left(\mathrm{kg} / \mathrm{m}^{3}\right)$ & 1050 \\
Specific heat of blood $\left(\mathrm{J} / \mathrm{kg}^{\circ} \mathrm{C}\right)$ & 3770 \\
Blood perfusion in tissue $(\mathrm{ml} / \mathrm{s} / \mathrm{ml})$ & 0.005 \\
Metabolic heat generation $\left(\mathrm{W} / \mathrm{m}^{3}\right)$ & 4200 \\
Latent heat $\left(\mathrm{J} / \mathrm{m}^{3}\right)$ & 250000 \\
The upper limit of phase change temperature $\left({ }^{\circ} C\right)$ & -1 \\
The lower limit of phase change temperature $\left({ }^{\circ} C\right)$ & -8 \\
Arterial blood temperature $\left({ }^{\circ} C\right)$ & 37 \\
\hline
\end{tabular}

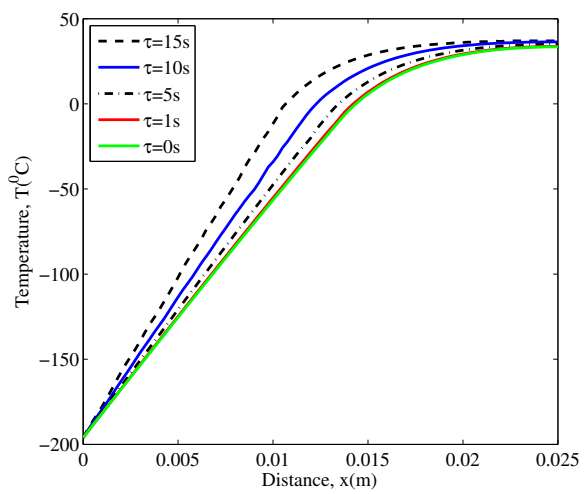

Figure 2. Temperature profile at $t=400 \mathrm{~s}$ for the value of $\tau=15 \mathrm{~s}, \tau=10 \mathrm{~s}, \tau=5 \mathrm{~s}$,

$$
\tau=1 s, \tau=0 s .
$$

solution is more evident. The tissue temperature for the hyperbolic model at the same time is higher than the parabolic model. The temperature increases in the tissue with an increase in the thermal relaxation time. It is clear that the parabolic model predicts a lower temperature then that of the hyperbolic model, and as the value of $\tau$ increases, the difference between the predicted temperature through the parabolic and hyperbolic models becomes greater.

The liquidus and solidus interface position during the freezing process for both parabolic and hyperbolic models are shown in Figure 4 and Figure 5 respectively. The time required to reach interfaces at $x=l$ are given in Table 2 . From Table 2 and Figure 4 and Figure 5 it is observed that phase change interfaces for hyperbolic model move slower than parabolic one. Further decrease in phase change interfaces movement is observed with an increase of value $\tau$ for hyperbolic model.

To study the effect of time relaxation parameter on temperature change 


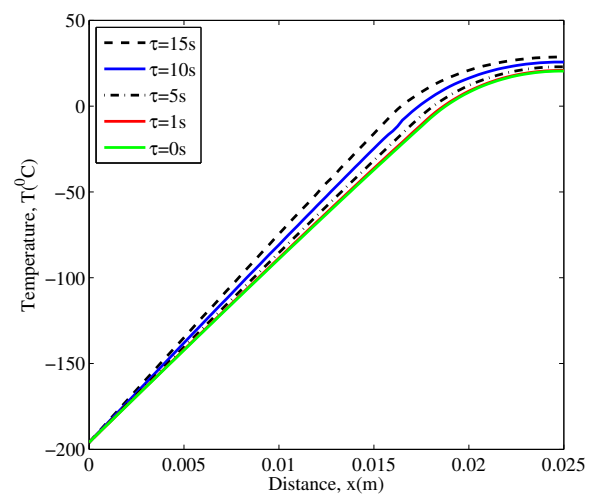

Figure 3. Temperature profile at $t=800 \mathrm{~s}$ for the value of $\tau=15 \mathrm{~s}, \tau=10 \mathrm{~s}, \tau=5 \mathrm{~s}$, $\tau=1 s, \tau=0 s$.

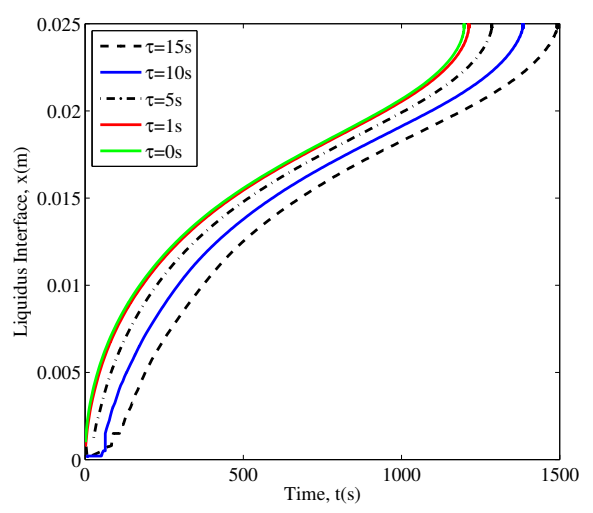

Figure 4. Liquidus interface position for the value of $\tau=15 s, \tau=10 s, \tau=5 s, \tau=1 s$,

$$
\tau=0 s .
$$

with respect to time at a point, temperature profiles are plotted in Figure 6 and Figure 7 at two test point $P(x=0.01 \mathrm{~m})$ and $Q(x=0.02 \mathrm{~m})$ respectively. From Figure 6 and Figure 7, it is observed that the parabolic model predicts lower temperature for tissues than the hyperbolic model at the same time. It is observed, that the points closer to the cooling boundary have a lower temperature then that of the further points. It is clear that the solidification process for the area closer to the cooling boundary occurs in a shorter time than that of the farther area to the cooling boundary, because the temperature gradient at the closer points to the cooling boundary is higher. Also the effect of thermal relaxation time on the temperature distribution is clear. The freezing process for hyperbolic model is slower than parabolic model.

From the above study, it is observed that between the hyperbolic and parabolic model freezing is faster for parabolic model based on Fourier's law which assumes infinite propagation speed of thermal disturbance i.e. heat is 


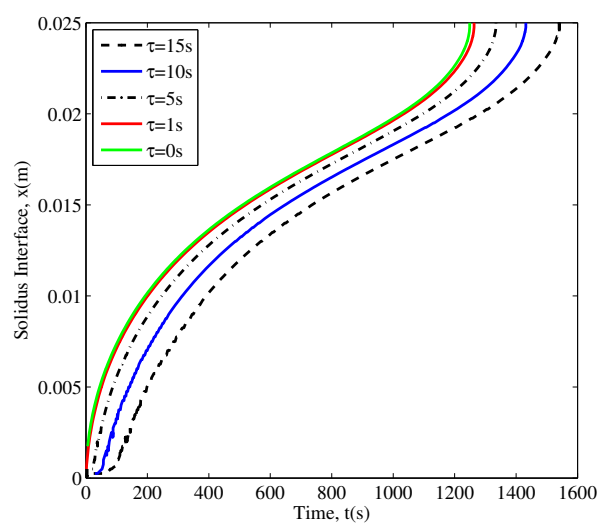

Figure 5. Solidus interface position for the value of $\tau=15 s, \tau=10 s, \tau=5 s, \tau=1 s$, $\tau=0 s$.

Table 2. Time to penetrate $x=l$ during freezing interfaces for different values of relaxation time $\tau$ for heat flux.

\begin{tabular}{lll}
\hline & \multicolumn{2}{c}{ Time taken to reach interface at $x=l$} \\
\cline { 2 - 3 } Relaxation time for heat flux $\tau$ & liquidus & solidus \\
\hline 0 & 1197.80 & 1248.81 \\
1 & 1212.91 & 1263.18 \\
5 & 1285.77 & 1334.46 \\
10 & 1384.22 & 1431.76 \\
& 1493.40 & 1540.64 \\
\hline
\end{tabular}

transferred into the tissue without delay. However in case of hyperbolic model the heat flux has a memory to keep track of time history and temperature gradient due to time lag in heat flux. Since the heat flux at certain time $t$ depends on the entire history of temperature gradient, the freezing for hyperbolic model is slower than parabolic model.

\section{Conclusions}

In this paper, an enthalpy formulation was used to develop the Fourier and nonFourier phase change heat conduction model in biological tissues during freezing process considering heat source term due to blood perfusion and metabolism. Non-ideal property of tissue is also taken in consideration. It is noticed that the single phase lag solution for small value of relaxation time approaches to the parabolic solution. The time required for complete tissue solidification in the parabolic model is shorter than that of the hyperbolic model. Further decrease in freezing position is observed with an increase of value $\tau$. The area which is near to the cooling boundary required a small time for freezing than that of the farther area from the cooling boundary. 


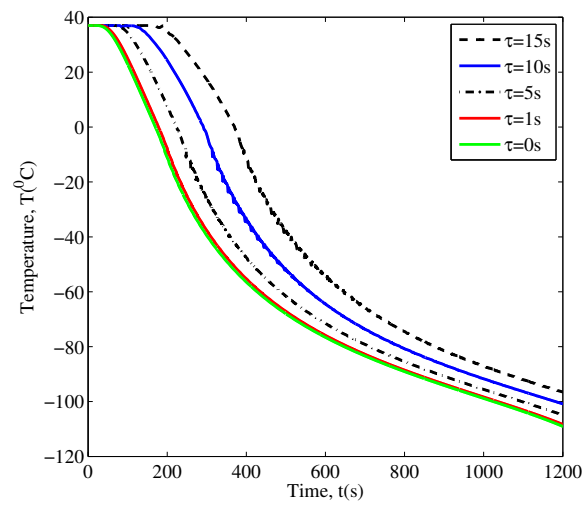

Figure 6. Temperature history at the point $x=0.01 \mathrm{~m}$ for the time relaxation value $\tau=15 s, \tau=10 s, \tau=5 s, \tau=1 s, \tau=0 s$.

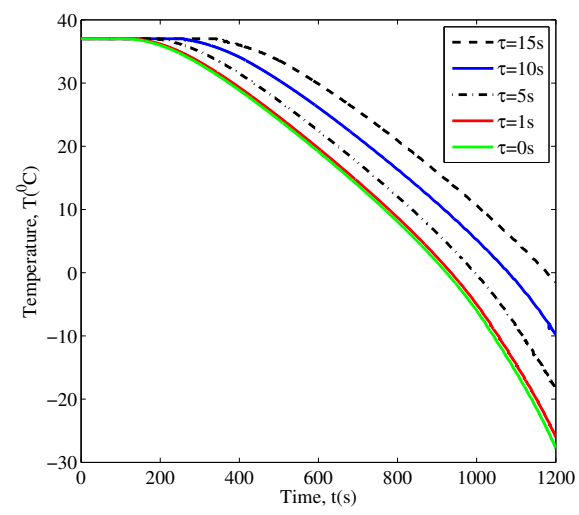

Figure 7. Temperature history at the point $x=0.02 \mathrm{~m}$ for the time relaxation value $\tau=15 s, \tau=10 s, \tau=5 s, \tau=1 s, \tau=0 s$.

\section{Acknowledgement}

One of the authors Sonalika Singh is thankful to S. V. National Institute of Technology, Surat, India for providing Senior Research Fellow (SRF) during the preparation of this manuscript.

\section{References}

[1] H. Ahmadikia and A. Moradi. Non-fourier phase change heat transfer in biological tissues during solidification. Heat Mass Transfer, 48(9):1559-1568, 2012. http://dx.doi.org/10.1007/s00231-012-1002-1.

[2] H. Ahmadikia, A. Moradi, R. Fazlali and B.A. Parsa. Analytical solution of non-Fourier and Fourier bioheat transfer analysis during laser irradiation of skin 
tissue. J. Mech. Sci. Technol., 26(6):1937-1947, 2012.

http://dx.doi.org/10.1007/s12206-012-0404-9.

[3] H. Aminikhah and J. Alavi. Applying cubic B-spline quasi-interpolation to solve $1 \mathrm{~d}$ wave equations in polar coordinates. ISRN Computational Mathematics, 2013, 2013. http://dx.doi.org/10.1155/2013/710529.

[4] J.C. Bischof, J. Bastacky and B. Rubinsky. An analytical study of cryosurgery in the lung. J. Biomech. Eng., 114(4):467-472, 1992.

http://dx.doi.org/10.1115/1.2894096.

[5] C. Bonacina, G. Comini, A. Fasano and M. Primicerio. Numerical solution of phase-change problems. Int. J. Heat Mass Trans., 16(10):1825-1832, 1973. http://dx.doi.org/10.1016/0017-9310(73)90202-0.

[6] H. Budman, A. Shitzer and D.S. Giudice. Investigation of temperature fields around embedded cryoprobes. J. Biomech. Eng., 108(1):42-48, 1986. http://dx.doi.org/10.1115/1.3138578.

[7] C. Cattaneo. Sur une forme de l'équation de la chaleur éliminant le paradoxe d'une propagation instantanée. C. R. Acad. Sci., 247:431-433, 1958.

[8] M.M. Chen and K.R. Holmes. Microvascular contributions in tissue heat transfer. Ann. N. Y. Acad. Sci., 335(1):137-150, 1980. http://dx.doi.org/10.1111/j.1749-6632.1980.tb50742.x.

[9] K.J. Chua, S.K. Chou and J.C. Ho. An analytical study on the thermal effects of cryosurgery on selective cell destruction. J. Biomech., 40(1):100-116, 2007. http://dx.doi.org/10.1016/j.jbiomech.2005.11.005.

[10] R. Čiegis. Numerical solution of hyperbolic heat conduction equation. Math. Model. Anal., 14(1):11-24, 2009. http://dx.doi.org/10.3846/1392-6292.2009.14.11-24.

[11] R. Čiegis, A. Dement'ev and G. Jankevičiūtè. Numerical analysis of the hyperbolic two-temperature model. Lithuanian Math. J., 48(1):46-60, 2008.

http://dx.doi.org/10.1007/s10986-008-0005-6.

[12] T.E. Cooper and G.J. Trezek. Rate of lesion growth around spherical and cylindrical cryoprobes. Cryobiology, 7(4):183-190, 1971. http://dx.doi.org/10.1016/0011-2240(70)90020-9.

[13] Z.S. Deng and J. Liu. Non-fourier heat conduction effect on prediction of temperature transients and thermal stress in skin cryopreservation. J. Thermal Stresses, 26(8):779-798, 2003. http://dx.doi.org/10.1080/01495730390219377.

[14] Z.S. Deng and J. Liu. Modeling of multidimensional freezing problem during cryosurgery by the dual reciprocity boundary eelement method. Engineering Analysis with Boundary Elements, 28(2):97-108, 2004. http://dx.doi.org/10.1016/S0955-7997(03)00128-0.

[15] Z.S. Deng and J. Liu. Numerical simulation of 3D freezing and heating problem for combined cryosurgery and hyperthermia therapy. Numerical Heat Transfer: Part A, 46:587-611, 2004. http://dx.doi.org/10.1080/10407780490487740.

[16] S.K. Dey. A novel explicit finite difference scheme for partial differential equations. Math. Model. Anal., 4(1):70-78, 1999.

http://dx.doi.org/10.1080/13926292.1999.9637112.

[17] N.E. Hoffmann and J.C. Bischof. Cryosurgery of normal and tumor tissue in the dorsal skin flap chamber: part I-thermal response. J. Biomech. Eng., 123(4):301-309, 2001. http://dx.doi.org/10.1115/1.1385838. 
[18] M.E. Honnor and A.J. Davies. Nonlinear transient field problems with phase change using the boundary element method. Eng. Anal. Bound. Elem., 28(6):561-570, 2004. http://dx.doi.org/10.1016/j.enganabound.2003.09.001.

[19] J.S. Hsiao and B.T.F. Chung. An efficient algorithm for finite element solution to two-dimensional heat transfer with melting and freezing. J. Heat Transfer, 108(2):462-464, 1986. http://dx.doi.org/10.1115/1.3246948.

[20] L.M. Jiji, S. Weinbaum and D.E. Lemons. Theory and experiment for the effect of vascular microstructure on surface tissue heat transfer-part II: Model formulation and solution. J. Biomech. Eng., 106(4):331-341, 1984. http://dx.doi.org/10.1115/1.3138502.

[21] S. Kumar, S. Ali and V.K. Katiyar. A parametric study on phase change heat transfer process during cryosurgery of lung tumor. Indian Journal of Biomechanics: Special Issue, pp. 210-213, 2009.

[22] S. Kumar and V.K. Katiyar. Numerical study on phase change heat transfer during combined hyperthermia and cryosurgical treatment of lung cancer. Int. J. Appl. Math. Mech., 3(3):1-17, 2007.

[23] S. Kumar and V.K. Katiyar. Mathematical modeling of freezing and thawing process in tissues: A porous media approach. Int. J. Appl. Mech., 2(03):617-633, 2010. http://dx.doi.org/10.1142/S1758825110000688.

[24] E. Li, G.R. Liu, V. Tan and Z.C. He. An efficient algorithm for phase change problem in tumor treatment using $\alpha$ FEM. Int. J. Therm. Sci., 49(10):1954-1967, 2010. http://dx.doi.org/10.1016/j.ijthermalsci.2010.06.003.

[25] J. Liu, X. Chen and L.X. Xu. New thermal wave aspects on burn evaluation of skin subjected to instantaneous heating. Biomedical Engineering, IEEE Transactions on, 46(4):420-428, 1999.

[26] K.C. Liu. Thermal propagation analysis for living tissue with surface heating. Int. J. Therm. Sci., 47(5):507-513, 2008. http://dx.doi.org/10.1016/j.ijthermalsci.2007.04.005.

[27] E. Majchrzak and L. Turchan. Numerical modeling of a hyperthermia therapy using dual-phase-lag model of bioheat transfer. In 19th International Conference on Computer Methods in Mechanics CMM, Ordinary Differential Equations, pp. 337-338, 2011.

[28] A. Moradi and H. Ahmadikia. Numerical study of the solidification process in biological tissue with blood flow and metabolism effects by the dual phase lag model. Proceedings of the Institution of Mechanical Engineers, Part H: Journal of Engineering in Medicine, 226(5):406-416, 2012. http://dx.doi.org/10.1177/0954411912441305.

[29] E.Y.K. NG and N.M. Sudharsan. Bench marking the bioheat equation for finite element analysis. Computer Methods in Biomechanics $\&$ Biomedical Engineering, pp. 231-236, 2001.

[30] P. Nithiarasu. An adaptive finite element procedure for solidification problems. Heat Mass Transfer, 36(3):223-229, 2000. http://dx.doi.org/10.1007/s002310050389.

[31] H.H. Pennes. Analysis of tissue and arterial blood temperatures in the resting forearm. J. Applied Physiology, 1:93-122, 1948.

[32] Y. Rabin and A. Shitzer. Exact solution to the one-dimensional inverse-Stefan problem in nonideal biological tissues. J. Heat Trans., 117(2):425-431, 1995. http://dx.doi.org/10.1115/1.2822539. 
[33] Y. Rabin and A. Shitzer. Combined solution of the inverse stefan problem for successive freezing/thawing in nonideal biological tissues. J. Biomech. Eng., 119(2):146-152, 1997. http://dx.doi.org/10.1115/1.2796073.

[34] Y. Rabin and A. Shitzer. Numerical solution of the multidimensional freezing problem during cryosurgery. J. Biomech. Eng., 120(1):32-37, 1998. http://dx.doi.org/10.1115/1.2834304.

[35] J.C. Rewcastle, G.A. Sandison, K. Muldrew, J.C. Saliken and B.J. Donnelly. A model for the time dependent three-dimensional thermal distribution within iceballs surrounding multiple cryoprobes. Medical Physics, 28(6):1125-1137, 2001. http://dx.doi.org/10.1118/1.1374246.

[36] S. Saedodin, M. Torabi, H. Eskandar and M. Akbari. Analytical and numerical solution of non-fourier heat conduction in cylindrical coordinates. J. Computat. Anal. Appl., 13(3):411-424, 2011.

[37] K.K. Sharma and P. Singh. Hyperbolic partial differential-difference equation in the mathematical modeling of neuronal firing and its numerical solution. Appl. Math. Comput., 201(1):229-238, 2008.

http://dx.doi.org/10.1016/j.amc.2007.12.051.

[38] M. Torabi and S. Saedodin. Analytical and numerical solutions of hyperbolic heat conduction in cylindrical coordinates. J. Thermophysics Heat Trans., 25(2):239253, 2011. http://dx.doi.org/10.2514/1.51395.

[39] P. Vernotte. Les paradoxes de la théorie continue de l'équation de la chaleur. $C$. R. Acad. Sci., 246:3154-3155, 1958.

[40] A. Weill, A. Shitzer and P.B. Yoseph. Finite element analysis of the temperature field around two adjacent cryo-probes. J. Biomech. Eng., 115(4A):374-379, 1993. http://dx.doi.org/10.1115/1.2895500.

[41] S. Weinbaum and L.M. Jiji. A new simplified bioheat equation for the effect of blood flow on local average tissue temperature. J. Biomech. Eng., 107(2):131139, 1985. http://dx.doi.org/10.1115/1.3138533.

[42] S. Weinbaum, L.M. Jiji and D.E. Lemons. Theory and experiment for the effect of vascular microstructure on surface tissue heat transfer-part I: Anatomical foundation and model conceptualization. J. Biomech. Eng., 106(4):321-330, 1984. http://dx.doi.org/10.1115/1.3138501.

[43] J. Zhang, G.A. Sandison, J.Y. Murthy and L.X. Xu. Numerical simulation for heat transfer in prostate cancer cryosurgery. J. Biomech. Eng., 127(2):279-294, 2005. http://dx.doi.org/10.1115/1.1865193.

[44] G. Zhao, H.F. Zhang, X.J. Guo, D.W. Luo and D.Y. Gao. Effect of blood flow and metabolism on multidimensional heat transfer during cryosurgery. Medical Engineering \& Physics, 29(2):205-215, 2007.

http://dx.doi.org/10.1016/j.medengphy.2006.03.005. 